\title{
The molecular and cellular basis of corticosteroid resistance
}

\author{
I C Chikanza, D Kozaci and Y Chernajovsky \\ Bone and Joint Research Unit, John Vane Building, St Bartholomew's and Royal London School of Medicine and Dentistry, Charterhouse Square, London \\ EC1M 6BQ, UK \\ (Requests for offprints should be addressed to I C Chikanza; Email: i.c.chikanza@qmul.ac.uk)
}

\begin{abstract}
Corticosteroids (CS) can modulate gene expression and are often used to treat a range of immunological and inflammatory diseases such as asthma, inflammatory bowel disease and rheumatoid arthritis. However, a proportion of patients fail to show an adequate response. On this basis patients have been subdivided into CS-sensitive (SS) and -resistant (SR) subgroups. The ability of CS to inhibit peripheral blood $\mathrm{T}$ cell proliferation in vitro has also been used similarly. In rheumatoid arthritis (RA), the in vitrodefined SS and SR subgroups correlate with the clinical responses to CS therapy. The mechanisms responsible for this observation are unknown but they appear to involve a number of known molecular events related to the described mechanisms of action of CS. These include alterations in the functional status of CS receptor- $\alpha$, perturbations of the cytokine and hormonal milieu and intracellular signalling pathways. Peripheral blood mononuclear cells (MNCs) from SR significantly overexpress
\end{abstract}

activated NF-кB. In vitro, CS fail to significantly inhibit concanavalin A (conA)-induced NF- $\mathrm{KB}$ activation in MNCs from SR RA patients. The alterations in the intracellular signalling pathways may explain in part our observations seen in SR RA subjects, CS fail to significantly inhibit conA-induced interleukin (IL)-2 and IL-4 secretion and lipopolysaccharide-induced IL-8 and IL-1 $\beta$ secretion in vitro. CS therapy fails to reduce the circulating levels of IL-8 and IL-1 $\beta$ in RA patients. In asthma, CS fail to induce L10 in SR asthma patients. Other molecular mechanisms such as enhanced AP-1 expression and alterations in the MAP kinase pathway are most likely to be involved too and we are currently investigating such possibilities. A full understanding of the molecular basis of SR will lead to the development of more rational therapeutic strategies.

Journal of Endocrinology (2003) 179, 301-310

\section{Introduction}

The acute inflammation which can be initiated by a number of inflammatory triggers is a programmed orchestrated sequence of physiological processes which begins with the release of pro-inflammatory cytokines such as tumour necrosis factor- $\alpha$ (TNF- $\alpha)$, interleukin (IL)-1 $\beta$ and IL-6 (Chikanza \& Grossman 2000). These inflammatory mediators activate a cascade of local and systemic responses which are central to the inflammatory response. The immune and neuroendocrine systems interact in a reciprocal manner both locally and systemically, which involves increased secretion of corticosteroids (CS) due to activation of the neuroendocrine-release mechanisms (Chikanza \& Grossman 2000). If acute inflammation is not restrained, it enters a chronic phase which is a central feature of many autoimmune diseases. These disorders are characterised at the molecular level by chronically increased expression of multiple pro-inflammatory cytokine genes.

IL-1 $\beta$, IL-6 and TNF- $\alpha$ play important roles in both acute and chronic inflammation and initiate a number of pro-inflammatory intracellular signalling events which include the activation of the transcriptional activities of AP-I and NF- $\kappa B$. These in turn enhance the production of a whole range of pro-inflammatory cytokines (Akira et al. 1990). These cytokines also induce the secretion of macrophage inhibitory factor (MIF) centrally and locally, which counteracts the effects of CS (Calandra \& Bucala 1997).

IL-1 $\beta$ and TNF- $\alpha$ activate the second wave of cytokinerelease mechanisms (IL-8, IL-12, IL-15, IL-17, IL-18, interferon (IFN)- $\alpha$ and $-\beta$, granulocyte colony-stimulating factor, fibroblast growth factor etc.) that augment the homeostatic signals necessary for the subsequent complex cellular/cytokine cascades of reactions, endothelial 
activation and enhanced cell adhesion. These changes in the microvasculature are facilitated by vasodilation, increased blood flow and permeability.

A number of other mediators of inflammation are released within the inflammatory foci and include: kinins secreted by basophil and mast cells; prostaglandins $\left(\mathrm{I}_{2}, \mathrm{D}_{2}\right.$, $\left.\mathrm{E}, \mathrm{F}_{2 \alpha}\right)$; platelet activating factor; neuropeptides such as calcitonin gene-related peptide and substance $\mathrm{P}$ released from eosinophils and nerve terminals; prolactin from $\mathrm{T}$ and $\mathrm{B}$ cells; corticotrophin-releasing hormone; reactive oxygen species and nitric oxide. Bradykinins, substance $\mathrm{P}$ and prostanoids may also stimulate pain pathways - the 'dolor' and 'functio laesio' of inflammation.

Under normal physiological conditions, the body attempts to down-regulate inflammation by increasing CS production (Chikanza \& Grossman 2000). CS are natural anti-inflammatory hormones produced by the adrenal glands under the control of the hypothalamus. Synthetic CS analogues such as prednisolone have been made and are often used to treat chronic autoimmune inflammatory disease such as rheumatoid arthritis (RA), asthma and inflammatory bowel disease. They can effectively reduce the parameters of inflammation such as erythrocyte sedimentation rate (ESR) and C-reactive protein (CRP) and induce disease remission. However, in clinical practice, a proportion of some patients fail to respond adequately to CS therapy (Chikanza \& Panayi. 1993, Sher et al. 1994, Ayabe et al. 1997). On this basis, patients can be divided into CS-sensitive (SS) and -resistant (SR) subgroups. The underlying mechanisms involved in the SS and SR phenomenon remain unknown but are of considerable therapeutic interest. A number of abnormalities have been described in SR asthma and RA patients. These include enhanced c-Jun phosphorylation and CS receptor (CR) $\beta$ expression (Sher et al. 1994).

\section{Mechanisms of action of CS}

A number of mechanisms of action of CS have now been described. CS exert specific and non-specific non-genomic effects which are very rapid. The exact mechanisms involved in this aspect of their mode of action are unknown at the moment but appear to be related to alterations in the function of the cell membrane and/or are mediated via some unknown cell surface receptors. These effects include analgesia and alterations in adhesion molecule expression. They also have genomic effects which are mediated via the $\mathrm{CR}$ which has a modular structure whose principal functions of transactivation, DNA binding and ligand binding are localised to specific domains (Cato \& Wade 1996). Alternative mRNA splicing results in two isoforms, CR $\alpha$ and $\operatorname{CR} \beta$ (Encio \& Detera-Wadleigh 1991, Castro et al. 1996). Only CR $\alpha$ is able to bind CS. CR $\beta$ can act as a negative inhibitor of
CR $\alpha$ (Encio \& Detera-Wadleigh 1991, Castro et al. 1996) (Fig. 1). In the absence of ligand, CR $\alpha$ is predominantly maintained in the cytoplasm as an inactive multi-complex protein consisting amongst other proteins of two hsp90 molecules and a number of other proteins such as immunophillin p59 and calreticulin. Binding of CS to the $\mathrm{CR} \alpha$ induces a conformational change and subsequent dissociation of the receptor from the multi-protein complex. Following the formation of the CS/receptor complex (CS/CR), CR dimerises, transactivates and then the CS/CR complex translocates to the nucleus to bind to specific DNA motifs, the glucocorticosteroid response elements (GREs) (Beato 1989). GRE can mediate both positive and negative effects (Akerblom et al. 1988, Beato 1989) (Fig. 2).

The CS/CR complex also interferes with the binding of AP-1 to its site on DNA (transrepression) (Cato \& Wade 1996) (Fig. 2). CS also up-regulate I $\mathrm{B} \alpha \alpha$ production which binds NF- $\mathrm{KB}$ to sequester it in the cytoplasm by masking the nuclear localising sequence (Auphan et al. 1995, Scheinman et al. 1995). NF- $\mathrm{KB}$ exists in the cytoplasm as a heterodimer (most commonly p50 and p65 subunits) bound to an inhibitor, IкB, which exists in a number of isoforms (Baeuerle \& Baltimore 1988, May \& Ghosh et al. 1999). Activation of cells by a variety of stimuli leads to the phosphorylation and

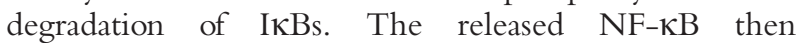
translocates to the nucleus to initiate transcription of target genes (Stocklin et al. 1996). AP-1 and NF-кB play central roles in the induction of a large number of important immune regulatory genes, including those encoding pro-inflammatory cytokines such as IL-1, IL-2, IL-3, IL-6, IL-8 and TNF- $\alpha$ as well as adhesion molecules. The CS/CR complex also interferes with the binding of NF- $\mathrm{\kappa B}$ to its site on DNA (transrepression). One feature that is common to $\mathrm{CR} \alpha$-mediated repression of both AP-1- and NF- $\kappa \mathrm{B}-$ dependent transcription is the mutuality of the effect. Not only is CR $\alpha$ capable of repressing AP-1 and NF- $\mathrm{NB}$, but both transcription factors may repress $\mathrm{CR} \alpha$-dependent transcription. CS also induces the production of an anti-inflammatory protein, lipocortin, by peripheral blood mononuclear cells (MNCs) which mediates a number of CS effects. The CR/CS complex also interacts with STAT5, and this association, which does not involve the binding of $\mathrm{CR} \alpha$ to the GRE, enhances the transcriptional activity of STAT5 to increase IL-2 receptor (IL-2R) $\alpha$ expression and $\beta$-casein production in mammary glands. CS also induce apoptosis of lymphocytes and thymocytes (Stocklin et al. 1996) (Fig. 3).

Regulated gene expression also requires the coordinated control of transcriptional (rate of gene transcription), post-transcriptional (mRNA stability), translational (protein synthesis), post-translational (protein processing, modification, degradation) events. It is most likely that some of these processes are also targets of CS action. 


\section{Human CR Gene}

\section{Transcription}
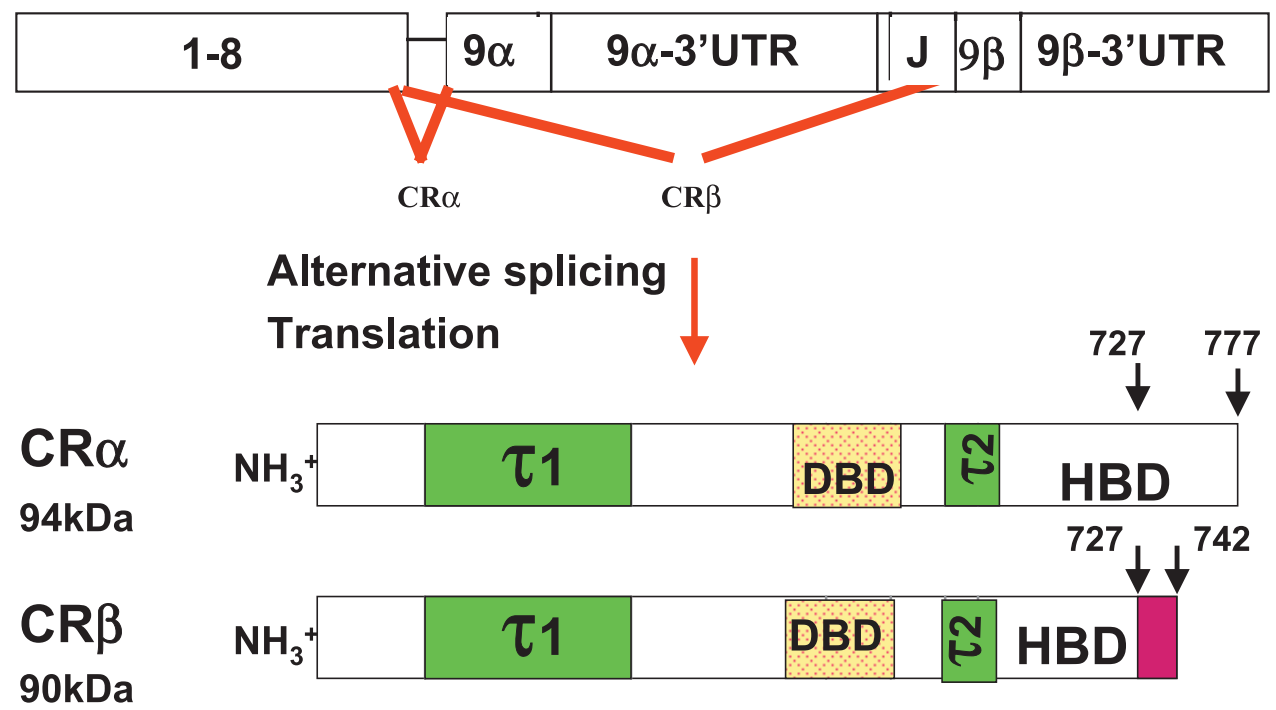

\section{HBD : Hormone binding domain \\ DBD : DNA-binding domain $\tau 1-2$ : transactivation domains}

Figure 1 The CS receptor (CR) has a modular structure whose principal functions of transactivation, DNA binding and ligand binding are localised to specific domains. Alternative mRNA splicing results in two isoforms CR $\alpha$ and CR $\beta$. Only CR $\alpha$ is able to bind CS. CR $\beta$ can act as a negative inhibitor of CR $\alpha$.

The physiological regulation of the antiinflammatory effects of CS: relevance to CS resistance

Unregulated CS effects can also have undesirable effects such as suppression of the body's ability to fight infections. Thus, as with most physiological systems, the body possesses counter-regulatory mechanisms to modulate these effects. These mechanisms include the role of cytokines and pro-inflammatory hormones such as prolactin (Clevenger et al. 1990, Sabharwal et al. 1992, Chikanza 1999, Chikanza \& Grossman 2000), corticotrophic hormone and substance $\mathrm{P}$, which are produced within inflammatory sites (Chikanza 1999), as well as alterations in the function of the CR $\alpha$. Overactivity in any of these mechanisms could potentially reduce the responses to CS.

\section{The role of hormonal counter-regulation}

Prolactin appears to have the greatest effect (Chikanza 1999). Prolactin is a pro-inflammatory neuropeptide produced by the pituitary and a number of extra-pituitary sites including MNCs which can act as an endogenous antagonist of CS (Bernton et al. 1988, Sabharwal et al. 1992, Sandi et al. 1992, Witorsch et al. 1993, Chikanza 1999). Structural analysis shows that prolactin is related to the members of the cytokine/haematopoietin family which include erythropoietin, granulocyte-macrophage colony-stimulating factor and IL-2 to IL-7 (Bazan 1990). It is an essential co-mitogen for $\mathrm{T}$ and $\mathrm{B}$ cells and can activate NK cells and macrophages (Clevenger et al. 1991, Matera et al. 1992). In vitro studies show that prolactin is required for IL-2 and IL-2R expression, which is essential for $\mathrm{T}$ cell activation and proliferation and enhances IFN- $\gamma$ production (Clevenger \& Medaglia 1991, Cesario et al. 1994, Benton et al. 1998). In vitro, prolactin reverses CS-induced apoptosis in $\mathrm{Nb} 2$ cells and abolishes the inhibitory effects of corticosterone on rat lymphocyte proliferation (Sandi et al. 1992, Witorsch et al. 1993). In vivo and ex vivo studies show that prolactin also antagonises the immunosuppressive effects of CS in murine species (Kelley et al. 1986, Bernton et al. 1988). Mice treated for 3 days with prolactin show reduced CS-induced immunosuppression. When splenic lymphoid cells from these mice are stimulated by mitogen in culture, 


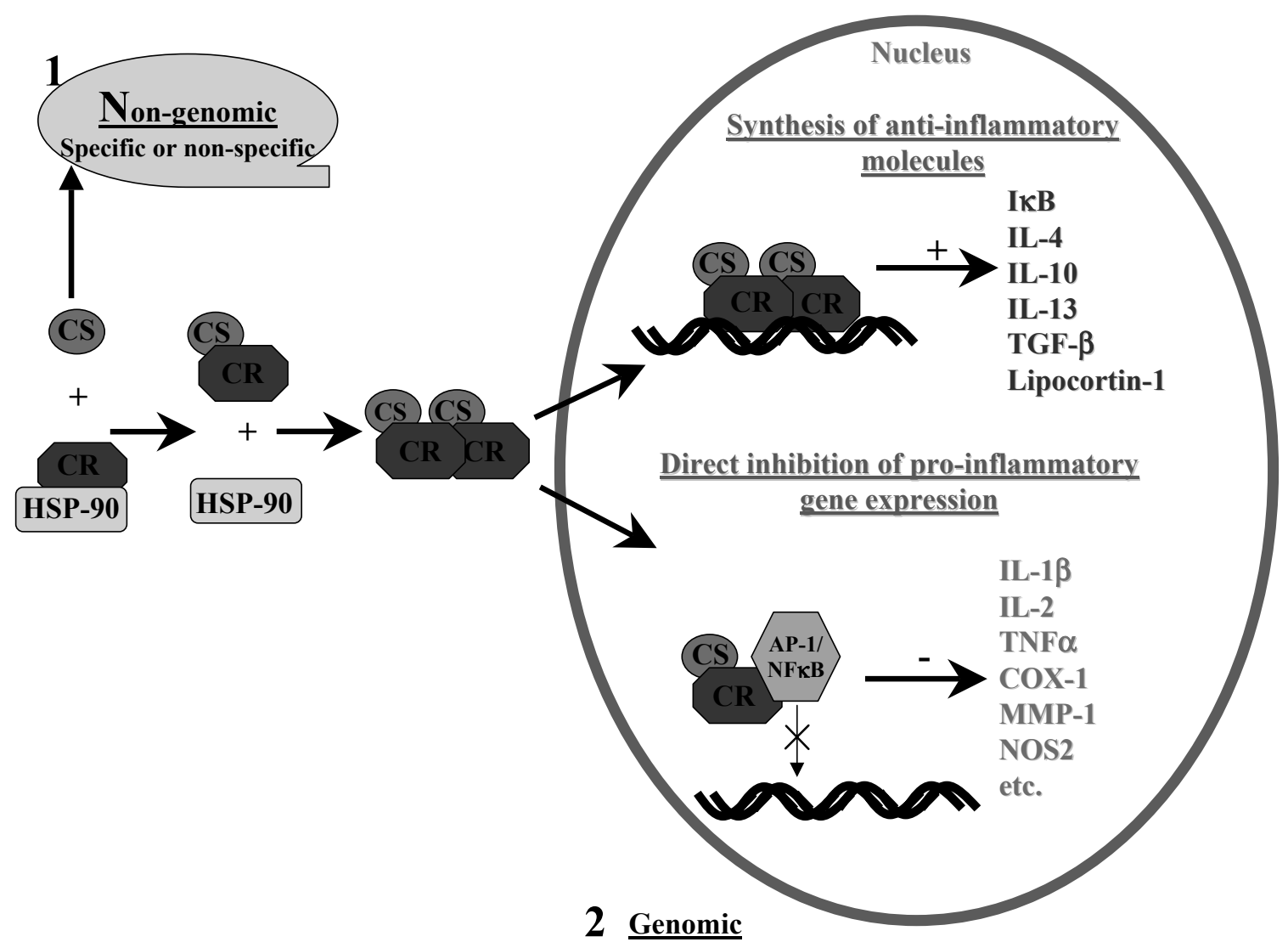

Figure 2 In the absence of ligand, $\mathrm{CR} \alpha$ is maintained in the cytoplasm as an inactive multi-complex protein consisting of two hsp90 molecules and other proteins such as immunophillin p59 and calreticulin. Binding of CS to the CR $\alpha$ leads to a conformational change of the CR and subsequent dissociation of the receptor from the multi-protein complex. Following the formation of the CS/CR complex, CR dimerises and transactivates and then the CS/CR complex translocates to the nucleus to bind to specific DNA motifs, the glucocorticosteroid response elements (GRE). CS/CR complex also interferes with the binding of AP-1 to its site on DNA (transrepression).

a 20- to 200-fold higher concentration of dexamethasone is needed to cause an equivalent suppression of cell proliferation when compared with control animals not treated with prolactin (Bernton et al. 1988). Thus, in vivo treatment with prolactin alters the sensitivity of lymphocytes to CS in vitro. Thus, at the neuroendocrine immune level, CS and prolactin antagonise each other, resulting in the titration of immune responses, suggesting that immunological homeostasis is maintained by a fine balance between the counteracting effects of these two hormones (Chikanza \& Grossman 1996).

Prolactin exerts its effects via prolactin receptors (Plr) found on macrophages and $\mathrm{T}$ and $\mathrm{B}$ cells (Clevenger $e t$ al. 1990, Dardenne et al. 1994). The binding of prolactin to Plr activates the JAK family of kinases which in turn phosphorylate and activate latent STAT5 (STAT5a and STAT5b) (Gouilleux et al. 1995, Ihle 1996, Ali 1998). This enables STAT5 to translocate to the nucleus and bind to respective STAT response elements on DNA leading to transcription (Ali 1998). STAT5 is also activated by cytokines such as IL-2 (Hou et al. 1995). Co-transfection studies in COS-7 cells show that hormone-activated CR $\alpha$ can form a complex with activated STAT5 (Clevenger \& Medaglia 1994). This complex enhances STAT5dependent transcription and would diminish the levels of free intracellular CS/CR $\alpha$ complexes leading to reduced GRE-mediated effects (Stocklin et al. 1996). The net effect would be increased levels of expression of activated $\mathrm{NF}-\kappa \mathrm{B}$ and STAT5 leading to reduced CS responsiveness (Fig. 4). Prolactin also induces signalling via the MAP kinase (MAPK) pathways involving the p56 Fyn/Shc/ SOS/Grb2/Ras/Raf/MAPK cascades (Clevenger \& Medaglia 1994, Erwin et al. 1995, Li et al. 1996). This pathway leads to increased levels of AP-1 (Karin 1995). Prolactin activates phosphatidylinositol-3-kinase which in turn leads to the activation of $A k t$ and subsequently IKB kinase complex, degradation of $\mathrm{I} \kappa \mathrm{B}$ and activation of NF- $\mathrm{BB}$ (Akerblom et al. 1988, Baeuerle \& Baltimore 1988, Almawi et al. 1991, Kam et al. 1993, Wu et al. 1993. Auphan et al. 1995, Scheinman et al. 1995, 


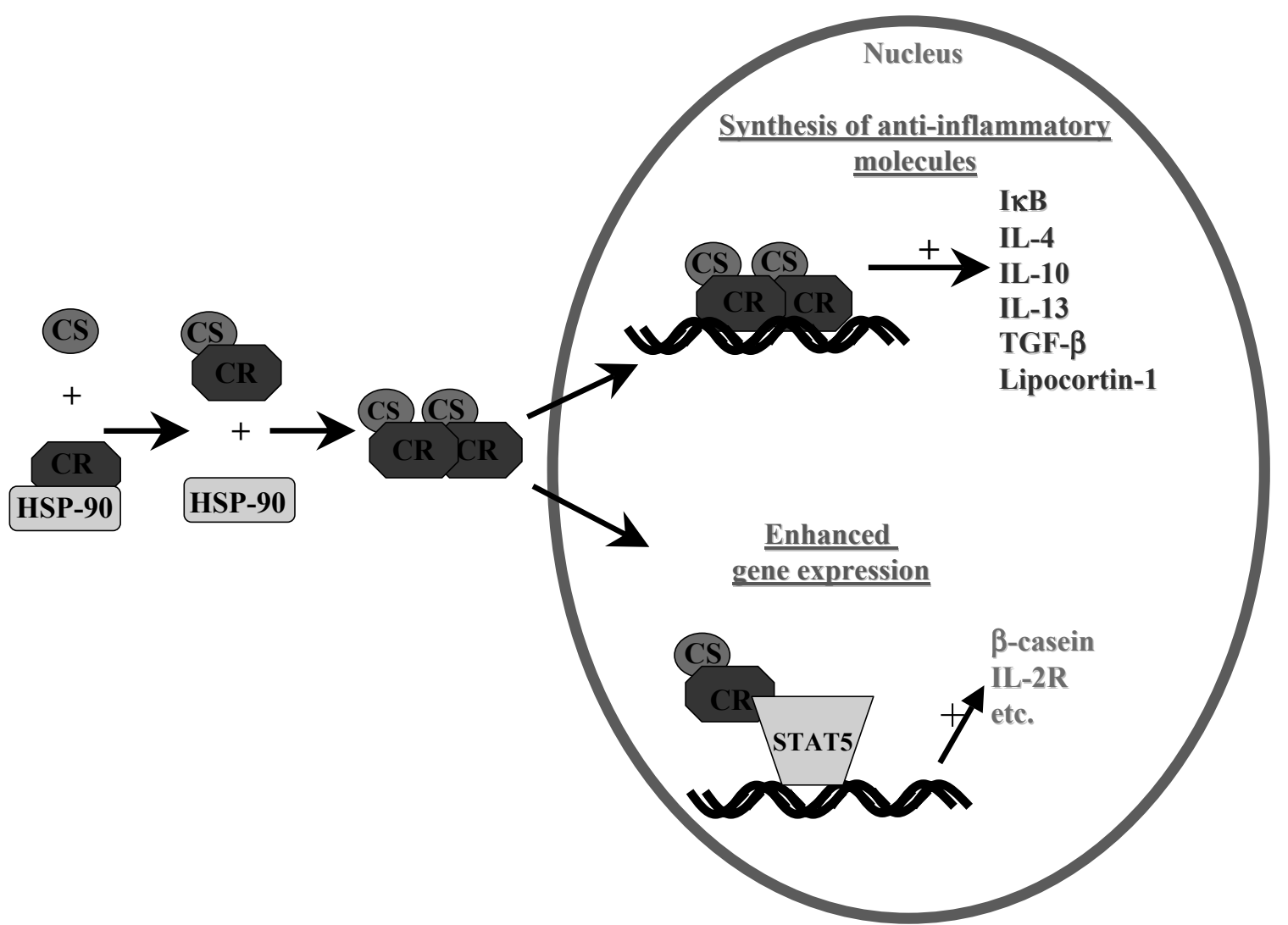

Figure 3 The CR/CS complex also interacts with STAT5 and this association, which does not involve the binding of CR $\alpha$ to the GRE, enhances the transcriptional activity of STAT5 to increase IL-2R $\alpha$ expression, $\beta$-casein production in mammary glands and that of other pro-inflammatory genes.

Stocklin et al. 1996, Berlanga et al. 1997 Leung et al. 1997). Thus, prolactin modulates immune system function by stimulating both cell proliferation and survival. Other neuropeptides which antagonise the effects of CS at the local level are corticotrophin-releasing hormones, substance $\mathrm{P}$ and arginine vasopressin (Chikanza \& Grossman 2000).

The relevance of these molecular observations to SR phenomenon is that: first, the overexpression of prolactin by MNCs could contribute to the reduced CS responsiveness phenomenon seen in some patients with RA, asthma and inflammatory bowel disease, since prolactin modulates immune system function by stimulating both cell proliferation and survival. Secondly, the local overproduction of corticotrophin-releasing hormone and/or substance $\mathrm{P}$ could also potentially contribute to this phenomenon. We are currently assessing these possibilities.

The role of cytokines in antagonising the effects of CS

MIF is also produced by the pituitary gland in parallel to increases in adrenocorticotrophin and also by macrophages in response to pro-inflammatory stimuli and low levels of CS $\left(10^{-12}-10^{-9} \mathrm{M}\right)$ (Calandra \& Bucala 1997). MIF antagonises the immunosuppressive effects of CS (Calandra \& Bucala 1997). MIF plays a regulatory role in $\mathrm{T}$ cell proliferation and IL-2 production (Bacher et al. 1996). This effect of MIF may be mediated in part via the increased expression of prolactin by MNCs since prolactin is an essential $\mathrm{T}$ cell growth (Chikanza 1999). IL-10 inhibits the expression of MIF by $\mathrm{T}$ cells as well as MIF-activated effector functions of macrophages (Wu et al. 1993). It is therefore possible that defective IL-10 production could lead to excessive MIF expression. Thus, by countering the effects of physiological CS, MIF and prolactin are involved in fine tuning of immune responsiveness.

What is the relevance of the cytokine milieu to CS resistance? The prevailing cytokine milieu may influence CS responsiveness. For instance in vitro, the addition of both IL-4 and IL-2 leads to reduced inhibition of cell proliferation by dexamethasone which may be mediated by alterations in CR mRNA splicing and the affinity of $\mathrm{CR} \alpha$ for CS as has been described in asthma patients (Kam et al. 1993, Leung et al. 1997). We have shown that CS fail to inhibit in vitro IL-2 and IL-4 production by blood cells 


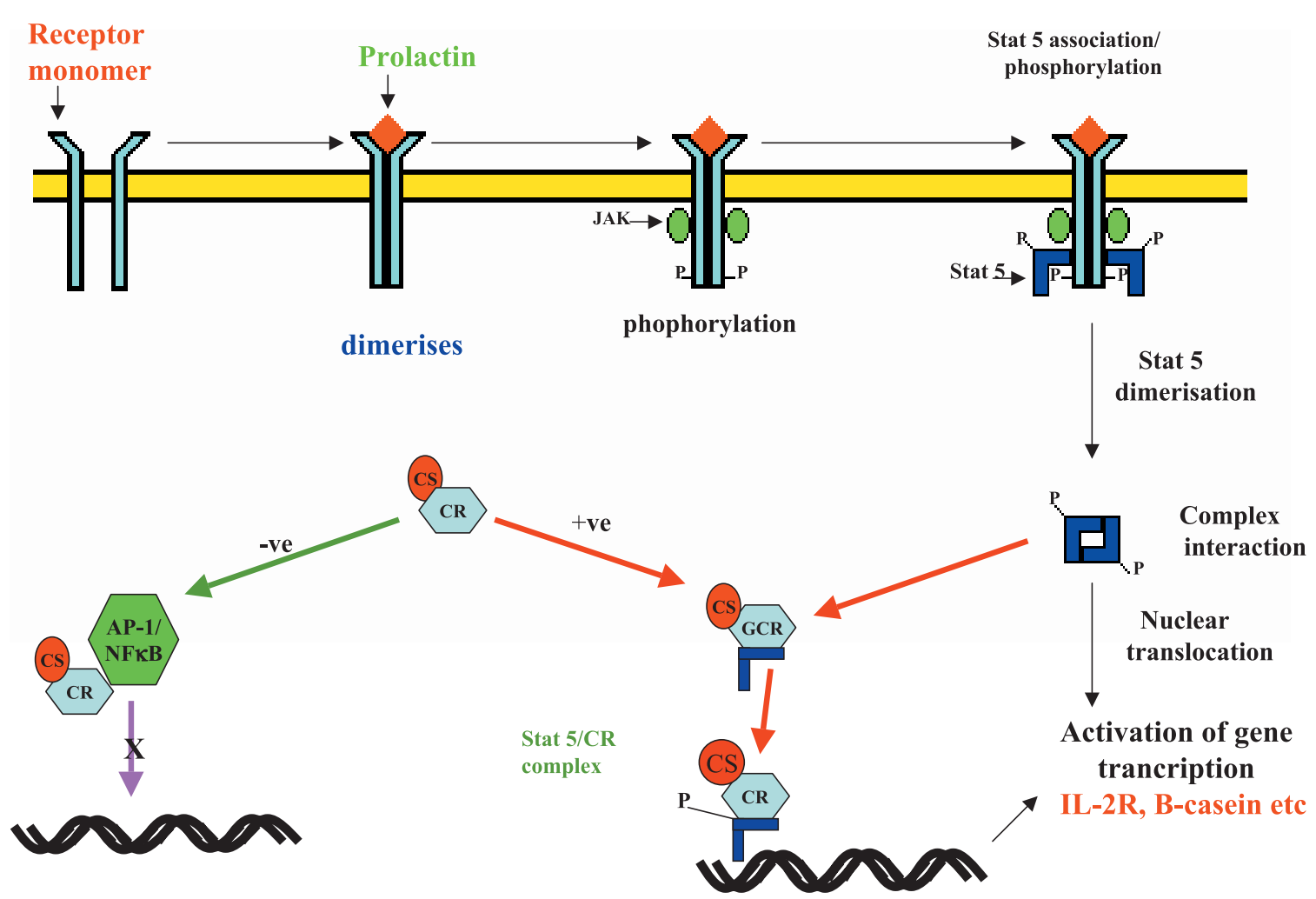

Figure 4 Prolactin exerts its effects via prolactin receptors (Plr) found on macrophages, $\mathrm{T}$ and B cells. The binding of prolactin to Plr activates the JAK family of kinases which in turn phosphorylate and activate latent STAT5 (STAT5a and STAT5b). This enables STAT5 to translocate to the nucleus and bind to respective STAT response elements on DNA leading to transcription. STAT5 is also activated by cytokines such as IL-2. CR $\alpha$ can form a complex with activated STAT5. This complex enhances STAT5-dependent transcription and would diminish the levels free intracellular CS/CR $\alpha$ complexes leading to reduced GRE-mediated effects. The net effect would be increased levels of expression of activated NF- $\mathrm{BB}$ and STAT5.

from SR RA patients (Chikanza \& Panayi 1993), whilst the circulating levels of MIF are increased in SR RA patients (Chikanza et al. 2003). IL-1 $\beta$, IFN- $\gamma$ and IL-6 synergistically abrogate CS-mediated inhibition of $\mathrm{T}$ cell proliferation (Almawi et al. 1991). On the other hand, CS fail to up-regulate IL-10 production in SR asthma patients (Hawrylowicz et al. 2002). Thus, perturbations of the cytokine milieu can have significant effects on the CS responsiveness.

\section{The corticosteroid receptor}

CR $\alpha$ mediates the effects of CS whilst CR $\beta$ is inhibitory (see Fig. 5). Alterations in the function of CR $\alpha$ therefore will reduce CS responsiveness. The failure by therapeutic CS doses to inhibit inflammatory disease in a number of conditions such as RA, asthma and inflammatory bowel disease has been intriguing. The concept of the SR phenomenon dates back to 1976 (Vingerhoeds et al. 1976). Vingerhoeds et al. reported a case of cortisol resistance in which high circulating cortisol blood levels were not associated with Cushing's syndrome but appeared to be related to a ligand affinity defect of the CR. Chrousos et al. (1982) and Lipsett et al. (1986) re-studied this family and demonstrated a defect in the affinity of CR for CS. Polymorphic alterations in the CR gene were proposed as the underlying molecular basis of SR in some patients. The term primary SR was suggested. In a more recent study, Huizenga et al. (2000) studied five patients with clinical cortisol resistance and found alterations in the receptor number and ligand affinity. PCR-single strand conformational polymophism sequence analysis showed no CR gene alterations (Huizenga et al. 2000). This suggests that alterations somewhere in the cascade of events starting with ligand binding to the CR, or alterations in the regulation of the expression of CSresponsive genes, or post-receptor defects of interaction with other nuclear factors formed the pathophysiological basis of cortisol resistance.

We do not know as yet whether the SR phenomenon seen in RA, asthma and inflammatory bowel disease patients is primary or secondary. The SS and SR phenotypes appear to be stable when tested repeatedly over time, 


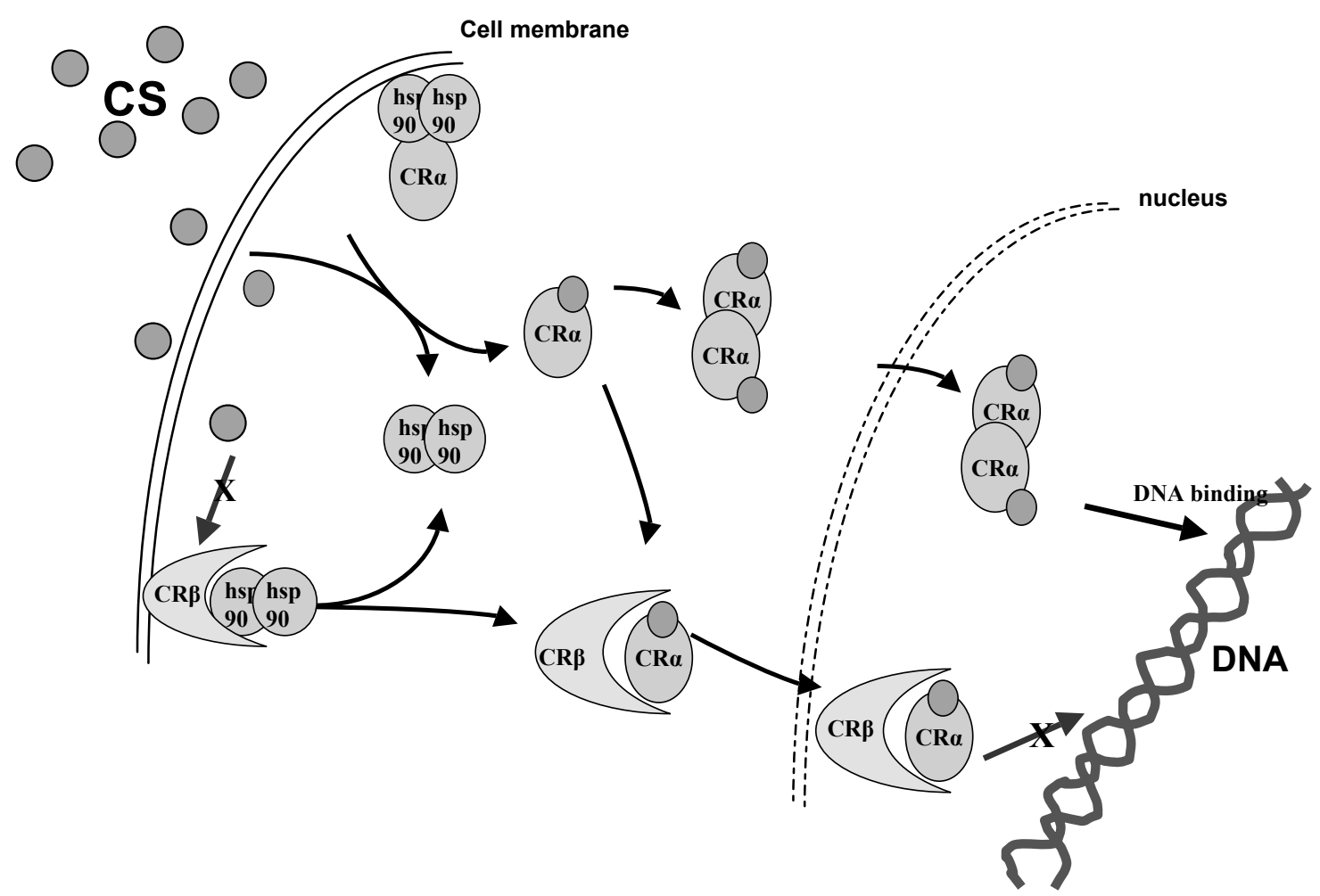

Figure 5 Schematic representation of the putative mechanisms of action of CR $\beta$ and CR $\alpha$. CR $\beta$ overexpression could reduce the CR $\alpha$-mediated cellular effects. CR $\beta$ can act as a negative inhibitor of CR $\alpha$ function. CR $\beta$ does not bind CS. It has been proposed that CR $\beta$ can compete with CR $\alpha$ for DNA binding at the glucocorticoid response element to form heterodimers with $\mathrm{CR} \alpha$ which are transcriptionally inactive or partially active (Burns et al. 1994). The CR $\beta / C R \alpha / C S$ heterodimer complexes do not bind as efficiently as the $\mathrm{CR} \alpha / \mathrm{CR} \alpha / \mathrm{CS}$ homodimers complexes to DNA and are not effective as and $\mathrm{CR} \alpha / \mathrm{CS}$ homodimers. $\mathrm{CS}=$ corticosteroid; $\mathrm{CR}=$ corticosteroid receptor; $\mathrm{X}=$ no binding.

suggesting that it may be an intrinsic property of the individual (Chikanza \& Panayi 1993). Alterations in a number of molecular events described in the mechanisms of CS may be involved in SR and include a dysregulation of CR $\alpha$ function and alterations of the intracellular signalling pathways. Lymphocytes from RA patients have decreased numbers of CR but this does not result in a significant reduction of cell sensitivity to CS in vitro. CS down-regulate CR $\alpha$ expression by lymphocytes from RA and normal subjects. Thus prolonged CS therapy may potentially reduce drug efficacy. In patients with polymyalgia rheumatica who often require prolonged CS therapy, this does not appear to be a problem in clinical practice. A dysregulation of the function of the CR $\alpha$ could result from alterations or a failure to properly regulate the cytokine milieu. First, CR $\beta$ overexpression could reduce the $\operatorname{CR} \alpha$-mediated cellular effects. $\operatorname{CR} \beta$ can act as a negative inhibitor of CR $\alpha$ function (Castro et al. 1996). Studies in asthma patients show that $\mathrm{CR} \beta$ is overexpressed by MNCs from SR asthmatics and that this can be enhanced further by treatment of cells with a combination of IL-2 and IL-4 (Leung et al. 1997). Whether a similar situation exists in RA and other chronic inflammatory autoimmune diseases remains to be determined. Our preliminary studies show that $\mathrm{CR} \beta$ is overexpressed in SR RA patients (Chikanza et al. 2000). There is, however, some controversy over the functional role of $\mathrm{CR} \beta$ in antagonising CR $\alpha$ (Hecht et al. 1997, de Lange et al. 1999). Whilst in transfection experiments, overexpression of CR $\beta$ reduces the effects of CS, the physiological relevance of this mechanism in vivo remains to be proven. We have previously shown that CS fail to inhibit IL-2 and IL-4 in MNC from SR RA patients and this could potentially lead to an overexpression of $\operatorname{CR} \beta$. The second mechanism relates to the overexpression of calreticulin, an important regulator of gene transcription induced by nuclear receptors, which can prevent the binding of CR $\alpha / \mathrm{CS}$ complex to the GRE (Burns et al. 1994, Dedhars et al. 1994). Overexpression of calreticulin in mouse L fibroblast cells inhibits the GRE transcriptional activity and blunts the interaction of CS/CR $\alpha$ complex with the GRE (Burns et al. 1994, Dedhars et al. 1994). Thus, its overexpression could potentially contribute to the SR phenomenon. Thirdly, polymorphic changes in the Hsp90 gene could result in alterations in the activation of the CR $\alpha$ following its binding to the CS resulting in 
either defective dimerisation or transactivation of the CR $\alpha / C S$ complex and therefore reduced CS genomic effects. There are many other co-factors involved in CR $\alpha$ transcription which include the Serc protein family. Alterations in the kinetics of Serc proteins may also have profound effects of CS responsiveness.

\section{Intracellular signalling mechanisms}

Pro-inflammatory cytokines initiate signalling via path-

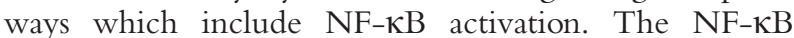
pathway is a target for CS. Thus, enhanced NF- $\kappa B$ expression could contribute to a state of reduced CS sensitivity. We have recently shown that the intracellular levels of activated (p65) NF- $\mathrm{\kappa B}$ are elevated in vivo in MNCs from SR RA patients and that CS fail in vitro to inhibit activation of NF- $\mathrm{KB}$ in cells from the SR subjects (Chikanza et al. 2000). This associated with a failure by $\mathrm{CS}$ to inhibit concanavalin A-induced degradation of IкB (Chikanza et al. 2000). On the other hand, overexpression of prolactin would enhance $\mathrm{NF}-\kappa \mathrm{B}$ and STAT5 activation.

Increased expression of activated STAT5 may occur as a primary event or could be linked to prolactin overexpression by inflammatory cells. STAT5 complexes with $\mathrm{CR} \alpha / \mathrm{CS}$ complex, sequestering the latter, and thus preventing its binding to the respective DNA site as well as diminishing the repressive effects of CR $\alpha / C S$ complex on AP-1 and NF- $\mathrm{KB}$ transcriptional activities. The STAT5/ CR $\alpha / C S$ complex enhances STAT5-mediated signalling which leads to increased expression of IL-2R and $\mathrm{T}$ cell activation (Stocklin et al. 1996). Thus, overexpression of STAT5 which could be secondary to prolactin overexpression and would contribute to a state of reduced CS responsiveness. This is an area in which there is intense research activity.

The utilisation of different activation pathways by $\mathrm{T}$ cells could contribute to a state of reduced CS responsiveness. This notion is supported by our observations which show that whilst concanavalin A-, phytohaemagglutinin- and lipopolysaccharide-induced proliferation of T cells is inhibited by CS in SS subjects with an $\mathrm{IC}_{50}$ of $10^{-6} \mathrm{M}$, the direct stimulation of highly purified T cells by cross-linking CD28 and CD3 receptors induces $\mathrm{T}$ cell proliferation as well as IL-2 production that are resistant to the effects of CS in SS subjects (I C Chikanza, unpublished observations).

\section{Conclusions}

CS resistance is a major therapeutic challenge in a number of human chronic autoimmune inflammatory diseases which include RA. A number of mechanisms have been described in asthma patients. The mechanisms in RA are essentially unknown but appear to involve a number of known molecular events related to the described mechanisms of action of CS. These include alterations in the functional status of CR $\alpha$, perturbations of the cytokine and hormonal milieu. There is now evidence that some intracellular signalling pathways may be dysregulated in cells from SR subjects with RA and asthma. The effects of $\mathrm{CS}$ are also mediated in part by the induction of lipocortin production by inflammatory cells. Lipocortin mediates some of the anti-inflammatory effects of CS. Thus, impaired lipocortin production and/or the presence of auto-antibodies to lipocortin could contribute to a state of reduced CS responsiveness. Finally, alterations in the bioavailability of CS may also play a part. It is most likely that in any one given individual and/or disease state, different mechanisms may be operative. The full understanding of the molecular basis of SR will lead to the development of more rational therapeutic strategies.

\section{Acknowledgement}

We are grateful to Mrs R Patel for secretarial assistance.

\section{Funding}

This work was supported by Arthritis Research Campaign.

\section{References}

Akerblom IE, Slater EP, Beato M, Baxter JD \& Mellon PL 1988 Negative regulation by glucocorticosteroids through interference with cAMP response enhancer. Science 241 350-353.

Akira S, Hirano T, Taga T \& Kishimoto T 1990 Biology of multifunctional cytokines: IL 6 and related molecules (IL 1 and TNF). FASEB Journal 4 2860-2872.

Ali S 1998 Prolactin receptor regulates STAT5 tyrosine phosphorylation and nuclear translocation by two separate pathways. Journal of Biological Chemistry 273 7709-7716.

Almawi Y, Lipman ML, Stevens AC, Zanker B, Had ET \& Strom TB 1991 Abrogation of glucocorticoid-mediated inhibition of T cell proliferation by the synergistic action of IL-1, IL- 6 and INF $\gamma$. Journal of Immunology 146 3523-3527.

Al-Sakkaf KA, Dobson PRM \& Brown BL 1996 Activation of phosphatidylinositol-3-OH kinase by prolactin in $\mathrm{Nb} 2$ cells. Biochemical and Biophysical Research Communications 221 779-784.

Auphan N, Didonato JA, Rosette C, Helmberg A \& Karin M 1995 Immunosuppression by glucocorticosteroids: inhibition of $\mathrm{NF}-\kappa \mathrm{B}$ activity through induction of $\mathrm{I} \kappa \mathrm{B} \alpha$ synthesis. Science $\mathbf{2 7 0}$ 286-290.

Ayabe T, Ashida T, Taniguchi M, Nomura M, Einami K, Taruishi M, Saitoh Y, Santos SB, Ono M, Shibata Y et al. 1997 A pilot study of centrifugal leukocyte apheresis for corticosteroid resistant active ulcerative colitis. Internal Medicine (Tokyo) 36 322-326.

Bacher M, Metz CN, Calandra T, Mayer K, Chesney J, Lohoff M, Gemsa D, Donnely T \& Bucala R 1996 An essential regulatory role for macrophage inhibitory factor in T cell activation. PNAS $\mathbf{9 3}$ 7849-7854. 
Baeuerle PA \& Baltimore D 1988 I $\kappa \mathrm{B} \alpha$ : a specific inhibitor of the NF-KB transcription factor. Science 242 540-546.

Bazan JF 1990 Haematopoietic receptors and helical cytokines. Immunology Today 11 350-354.

Beato M 1989 Gene regulation by steroid hormones. Cell 56 335-344.

Berlanga JJ, Gualillo O, Buteau H, Applant M, Kelly PA \& Edery M 1997 Prolactin activates trysosyl phosphorylation of insulin receptor substrate and phosphatidylinositol-3-OH kinase. Journal of Biological Chemistry 272 2050-2052.

Bernton EW, Meltzer MS \& Holaday JW 1988 Suppression of macrophage activation and $\mathrm{T}$ lymphocyte function in hypoprolactinemic mice. Science 239 401-404.

Burns K, Duggan B, Atkinson E, Famulski K, Nemer M, Bleackley C \& Michlak M 1994 Modulation of gene expression by calreticulin binding to the glucocrticosteroid receptor. Nature 367 476-483.

Calandra T \& Bucala R 1997 Macrophage inhibitory factor: a glucocorticoid counter-regulator within the immune system. Critical Reviews in Immunology 17 77-88.

Castro M, Elliot S, Kino T, Bamberger C, Karl M, Webster E \& Chrousos GP 1996 The non-ligand binding $\beta$-isoform of the human glucocorticosteroid receptor: tissue levels, mechanisms of action and potential physiologic role. Molecular Medicine 2 597-607.

Cato ACB \& Wade E 1996 Molecular mechanisms of antiinflammatory action of glucocorticosteroids. BioEssays 18 371-378.

Cesario TC, Yousefi S, Carandana G, Sadati N, Le J \& Vaziri N 1994 Enhanced yields of gamma interferon in prolactin treated human peripheral blood mononuclear cells. Proceedings of the Society for Experimental Biology and Medicine 205 89-95.

Chikanza IC 1999 Prolactin and neuroimmunomodulation: in vitro and in vivo observations. Annals of the New York Academy of Sciences $\mathbf{8 7 6}$ 131-144.

Chikanza IC \& Grossman A 1996 Neuroendocrine immune responses to inflammation: the concept of the neuroendocrine immune loop. Balliere's Clinical Rheumatology 10 199-226.

Chikanza IC \& Grossman AS 2000 Reciprocal interactions between the neuroendocrine and immune systems. Rheumatic Diseases Clinics of North America 26 693-712.

Chikanza IC \& Panayi GS 1993 The differential effects of hydrocortisone on in vitro lymphocyte proliferation, IL-2, IL-4 production in corticosteroid sensitivity and resistant rheumatoid patients. European Journal of Clinical Investigation 23 845-850.

Chikanza IC, Pearce GJ \& McCloskey DJ 2000 NF-кB activity in vivo is significantly upregulated in corticosteroid resistant rheumatoid arthritis patients. Rheumatology 39 (Suppl 1) 4.

Chikanza IC, Kozaci D \& Chernajovsky Y 2003 Up-regulation of macrophage inhibitory factor in corticosteroid resistant patients with rheumatoid arthritis. Rheumatology 4229.

Chrousos GP, Vingerhoeds A, Brandon D, Eil C, Pugeat M, DeVroede M, Loriaux DL \& Lipsett MB 1982 Primary cortisol resistance in man: a glucocorticoid receptor-mediated disease. Journal of Clinical Investigation 69 1261-1269.

Clevenger CV \& Medaglia MV 1994 The protein tyrosine kinase p56 fyn is associated with prolactin receptor and is activated by prolactin stimulation of T-lymphocytes. Molecular Endocrinology 6 674-681.

Clevenger CV, Russell DH, Appasamy PM \& Prytowsky MB 1990 Regulation of IL-2 driven T-lymphocyte proliferation by prolactin. PNAS 87 6460-6464.

Clevenger CV, Altmann SW \& Prystowsky MB 1991 Requirement of nuclear prolactin for interleukin 2 stimulated proliferation of $\mathrm{T}$ lymphocytes. Science 253 77-79.

Dardenne M, de Moraes Mdo C, Kelly PA \& Gagnerault MC 1994 Prolactin receptor expression in human hematopoietic tissues analyzed by flow cytofluorimetry. Endocrinology 134 2108-2214.

Dedhars S, Rennie PS, Shago M, Hagesteijin CYL, Yang H, Filmus J, Hawley RG, Bruchovsky N, Cheng H, Matusik RJ et al. 1994 Inhibition of nuclear hormone receptor activity by calreticulin. Nature 367 480-483.
Encio IJ \& Detera-Wadleigh SD 1991 The genomic structure of the human glucocorticosteroid receptor. Journal of Biological Chemistry $2667182-7188$.

Erwin RA, Kirken RA, Malbara MG, Farrar WL \& Rui H 1995 Prolactin activates Ras via signalling proteins SHC, growth factor receptor bound 2, and son of sevenless. Endocrinology 136 $3512-3518$

Gouilleux F, Moritz D, Humar M, Moriggl R, Berchtold S \& Groner B 1995 Prolactin and interleukin 2 receptors in T lymphocytes signal through a MGF-STAT5 like transcription factor. Endocrinology 136 5700-5708.

Hawrylowicz C, Richards D, Loke TK, Corrigan C \& Lee T 2002 A defect in corticosteroid-induced IL-10 production in T lymphocytes from corticosteroid-resistant asthmatic patients. Journal of Allergy and Clinical Immunology 109 369-370.

Hecht K, Carlstedt DJ, Stierna P, Gustafsson J, Bronnegard M \& Wikstrom AC 1997 Evidence that the beta isoform of the human glucocorticoid receptor does not act as a physiologically significant repressor. Journal of Biological Chemistry 272 26659-26664.

Hou J, Schindler U, Henzel WJ, Wong SE \& McKnight SC 1995 Identification and purification of human STAT proteins activated in response to IL-2. Immunity 2 321-329

Huizenga NA, de Lange P, Koper JW, de Herder WW, Abs R, Kasteren JH, de Jong FH \& Lamberts SW 2000 Five patients with biochemical and/or clinical generalized glucocorticoid resistance without alterations in the glucocorticoid receptor gene. Journal of Clinical Endocrinology and Metabolism 85 2076-2081.

Ihle JN 1996 STATs: Signal transducers and activation of transcription. Cell 84 331-334.

Kam JC, Szfler SJ, Surs W, Sher ER \& Leung DYM 1993 Combination of IL-2 and IL-4 reduces glucocorticoid receptor binding affinity and $\mathrm{T}$ cell response to glucocorticoids. Journal of Immunology 151 3460-3466.

Karin M 1995 The regulation of AP-1 activity by mitogen activated protein kinases. Journal of Biological Chemistry 270 16483-16486.

Kelley KW, Brief S, Westly HJ, Novakofski J, Bechtel PJ, Simon J \& Walker EB 1986 GH3 pituitary adenoma can reverse thymic ageing in rats. PNAS 83 5653-5657.

de Lange P, Koper JW, Brinkmann AO, de Jong FH \& Lamberts SW 1999 Natural variants of the beta isoform of the human glucocorticoid receptor do not alter sensitivity to glucocorticoids. Molecular and Cellular Endocrinology 153 163-168.

Leung DY, Hamid Q, Vottero A, Szefler SJ, Surs W, Minshall E, Chrousos G \& Klemm D 1997 Association of glucocorticosteroid insensitivity with increased expression of glucocorticosteroid receptor $\beta$. Journal of Experimental Medicine 186 1567-1574.

Li B, Subleski M, Fusaki Ni, Yamamoto T, Copeland T, Princler GL, Kung H \& Kamata T 1996 Catalytic activity of the mouse guaninine nucleotide exchanger mSOS is activated by Fyn tyrosine protein kinase and the T cell antigen receptor in T cells. PNAS 93 1001-1005.

Lipsett MB, Tomita M, Brandon DD, De Vroede MM, Loriaux DL \& Chrousos GP 1986 Cortisol resistance in man. In Steroid Hormone Resistance: Mechanisms and Clinical Aspects, pp 97-109. Eds GP Chrousos, DL Loriaux \& MB Lipsett. New York, NY: Plenum Press.

Matera L, Cesano A, Bellone G \& Oberholtzer E 1992 Modulatory effect of prolactin on the resting and mitogen induced activity of $T$, B and NK lymphocytes. Brain, Behaviour and Immunity 6 409-417.

May M \& Ghosh S 1999 IкB kinases: kinsmen with different crafts. Science 284 271-273.

Sabharwal P, Glaser R, Lafuse W, Varma S, Liu Q, Arkins S, Kooijman R, Kutz L, Kelley KW \& Malarkey WB 1992 Prolactin synthesized and secreted by human peripheral blood mononuclear cell and autocrine growth factor for lymphoproliferation. PNAS $\mathbf{8 9}$ $7713-7716$ 
Sandi C, Cambronero JC, Borrell J \& Guaza C 1992 Mutually antagonistic effects of corticosterone and prolactin on rat lymphocyte proliferation. Neuroendocrinology 56 574-581.

Scheinman RI, Cogswell PC, Lofquist AK \& Baldwin AS 1995 Role of transcriptional activation of $I \kappa \mathrm{B} \alpha$ in the mediation of immunosuppression by glucocorticosteroids. Science $\mathbf{2 7 0}$ 283-286.

Sher ER, Leung DY, Surs W, Kam JC, Kamada AK \& Szefler SJ 1994 Steroid-resistant asthma. Cellular mechanisms contributing to inadequate response to glucocorticoid therapy. Journal of Clinical Investigation 93 33-39.

Stocklin E, Wissler M, Gouilleux F \& Groner B 1996 Functional interactions between STAT5 and the glucocorticoid receptor. Nature 383 726-728.
Vingerhoeds ACM, Thijssen JHH \& Schwarz F 1976 Spontaneous hypercortisolism without Cushing's syndrome. Journal of Clinical Endocrinology and Metabolism 43 1128-1133.

Witorsch RJ, Day EB, Lavoie HA, Hashemi N \& Taylor NK 1993 Comparison of the glucocorticoid-induced effects in prolactin dependent and autonomous rat $\mathrm{Nb} 2$ lymphoma cells. Proceedings of the Society for Experimental Biology and Medicine 203 454-460.

Wu J, Cunha FQ, Liew FY \& Weiser W 1993 IL-10 synthesis inhibits the synthesis of MIF and MIF-mediated macrophage activation. Journal of Immunology 151 4325-4332.

Received in final form 30 June 2003

Accepted 10 July 2003 